\title{
LA COMPRENSIÓN MÁGICA DE LA FEMINIDAD. OPINIONES DEMONOLÓGICAS ACERCA DE LAS MUJERES Y LAS BRUJAS ${ }^{1}$
}

\author{
Alberto Ortiz \\ Universidad Autónoma de Zacatecas - México \\ albor2002@gmail.com
}

\begin{abstract}
¿Oís? Las brujas míseras venganza pidiendo están desde la fría tumba, y su agudo clamor sin esperanza en las oscuras bóvedas retumba:

No pactamos jamás con el demonio, dicen, fue levantado testimonio. $\mathrm{Ni}$ frotamos el cuerpo con unturas según nuestros verdugos afirmaban, ni en escobas volábamos a oscuras, ni chupábamos niños que mamaban; que si el vuelo a nosotras dado fuera la negra Inquisición no nos cogiera.

Valentín del Mazo y Correa, La bruja, el duende y la Inquisición.
\end{abstract}

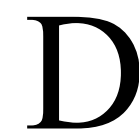
esde el Renacimiento hasta el inicio de la Ilustración, los discursos censores de corte escolástico contra la magia, la heterodoxia y las supersticiones conformaron la época de mayor difusión lírica y erudita de las ideas respecto a la brujería y la demonología; esta magna propaganda encaminada al

\footnotetext{
$1 \quad$ Este artículo se ha desarrollado dentro del proyecto «La mujer frente a la Inquisición española y novohispana» (FEM2016-78192-P), I+D de Excelencia del Ministerio de Economía y Competitividad (MINECO), financiado por la Agencia Estatal de Investigación (AEI) y el Fondo Europeo de Desarrollo Regional (FEDER, UE); y del grupo de investigación «Mentalidades mágicas y discursos antisupersticiosos (siglos XVI, XVII y XVIII)», grupo consolidado por la UAM.
}

Edad de Oro, XXXVIII (2019), pp. 17-34, ISSN: 0212-0429 - ISSNe: 2605-3314 
control de las creencias populares y a la uniformidad ideológica estuvo fortalecida por tratados, manuales inquisitoriales, sermones, obras literarias y una amplia gama de herramientas didácticas, censoras y coercitivas².

A través de esta gran etapa propagandística y restrictiva - en la que varios libros descriptivos para letrados y curas y frailes novatos, acerca de la adecuada persecución de brujas y demonios tuvieron un impresionante éxito editorial ${ }^{3}$-, la mayor parte de los especialistas en el tema, algunos de ellos connotados teólogos y demonólogos, sumaron a los relatos folclóricos, a las leyendas populares y a la percepción maravillosa y fantástica del mundo, relatos tan significativos como el pacto diabólico, el aquelarre ${ }^{4}$, la secta de los brujos y la posesión diabólica.

Dentro de la extensa mitología que la discusión contiene destaca la ubicuidad femenina en el contenido de la mayor parte de las diatribas y dilucidaciones para explicar la presencia del mal entre los hombres. El prejuicio no era nuevo. Desde la Antigüedad, las religiones troncales monoteístas habían establecido varias normas diferenciadoras y clasificadoras alrededor de las mujeres, en tanto sujetos aliados a la debilidad de carácter, la vulnerabilidad de pensamiento, la apetencia carnal, la filiación diabólica y la propensión al pecado, entre otros calificativos considerados reales defectos o peligrosas imperfecciones. Los autores destacados de la patrología instalaron conceptos irrevocables de autoridad en este y otros dilemas morales y teológicos. Santo Tomás, por ejemplo, al repartir las culpas, responsabiliza a Eva del pecado original, sintetizando una idea ya aceptada en su tiempo:

Como ya hicimos ver antes (a.3) la gravedad del pecado se mide por la misma especie de pecado más que por la circunstancia de quien lo comete. Hay que decir, por tanto, que, si consideramos la condición de ambas personas, hombre y mujer, es más grave el pecado del varón porque era más perfecto que la mujer.

En cuanto al género de pecado, fueron iguales, porque ambos cometieron pecado de soberbia. Por eso dice San Agustín, en XI Super Gen, ad litt., que la mujer pecó en sexo más débil, pero con un orgullo igual.

En cuanto a la especie de soberbia, en cambio, pecó más gravemente la mujer, por una triple razón. En primer lugar, porque su engreimiento fue mayor al creer que era cierto lo que le sugirió la serpiente [...] En segundo lugar, porque la mujer no sólo pecó, sino que indujo a pecar al varón, con lo cual pecó contra Dios y contra el prójimo. En tercer lugar, porque el pecado del hombre fue menor porque consistió en él por benevolencia de amistad, que casi siempre hace que se ofenda a Dios

2 María Jesús Zamora Calvo incluye un catálogo bibliográfico, completísimo, de este amplio corpus en su reciente libro Artes maleficorum. Brujas, magos y demonios en el Siglo de Oro.

3 El ejemplo de tal acogida e influencia está en las docenas de ediciones que durante aquella época tuvo el Malleus maleficarum.

4 En el libro El aquelarre. Mito, literatura y maravilla, he propuesto una explicación de los aspectos ficticios de este relato en particular. 
para evitar que el hombre se convierta de amigo en enemigo, aunque no por eso carece de maldad, según declara manifiestamente la sentencia de Dios, como dice San Agustín en XI Super Gen. Ad litt. Queda claro, pues, que el pecado de la mujer fue más grave que el del hombre (Santo Tomás 2005: 540-541).

Asentada la diferencia original entre hombre y mujer, la cual confiere a esta una imperfección natural, tácita, que luego devendrá en el prejuicio de la envidia fálica y la supuesta pecaminosa necesidad de sublevarse ante al varón en busca de una incorrecta igualdad, o incluso de una supremacía contranatura, y más grave, de hacerlo contra la voluntad divina; el teólogo dominico no necesita particularizar los yerros humanos en el género femenino: la interpretación subsecuente de sus textos, llevada a cabo por hermeneutas y comentadores, los detallan por él. Santo Tomás ni siquiera menciona las diferencias que aquí se afana en establecer cuando analiza y dictamina cuestiones espinosas como la superstición, la conjuración, la adivinación y la idolatría. En ninguno de esos libros señala a la mujer como causante, promotora o receptora de la maldad o el error. Solamente en este caso deja clara su posición respecto a las diferencias de género. Basta y sobra para oficializar el prejuicio frente al otro, debido a que, para todo creyente, la continuidad de la humanidad y de la historia cristiana proviene de los acontecimientos del Génesis.

Además, apenas con dos o tres frases lapidarias: «indujo a pecar al varón», «pecó contra Dios y contra el prójimo», en cuanto a la función de Eva como trasmisora del pecado, el padre de Aquino pergeña y, en cierto modo, preconiza, la dualidad culposa de la mujer bruja, pues, en suma, cada juicio en contra de las mujeres procesadas por la Inquisición contiene la exigencia de responder por las ofensas y delitos contra Dios y contra los hombres. Al mismo tiempo, su dictamen relativo a una madre de la humanidad crédula y débil ante las argucias del enemigo maligno, confirmará la diferenciación y servirá de argumento reiterado para los cazadores de brujas barrocos.

El discurso antisupersticioso remarca tal tendencia, lo que, a la luz de los actuales esfuerzos por establecer la equidad de género en la sociedad, ha merecido el epíteto de misógina ${ }^{5}$. Ahora bien, este tipo de denominaciones requiere de ajustes sincrónicos: se reitera que el uso y aplicación de un concepto actual a un fenómeno y momento histórico, ajenos a su definición y a su campo semántico, complica su correcta apreciación. Sin embargo, se mantiene aquí como herramienta teóricometodológica para los objetivos del análisis propuesto.

5 La definición del vocablo misoginia, hoy en día de uso común, dado por el Diccionario de la RAE, «Aversión a las mujeres» resulta insuficiente para definir la tradición que vincula al mal —en especial a la brujería y el pacto diabólico - con el género femenino. Solo para el presente texto, su definición deberá considerar la transición histórica de los prejuicios alrededor de la mujer, en especial, los emitidos por los teólogos eruditos cuando disertan en materia de magia y demonología. 
Parece inevitable que las opiniones eruditas alrededor de la brujería, redactadas y publicadas en sendos manuales inquisitoriales y tratados demonológicos, estén cargados de menosprecios, desdenes y medidas precautorias ante la identidad femenina; esto se debe a que la idiosincrasia de la época respecto a las mujeres correspondía a tradiciones patriarcales, y obviamente estaba constituida por fórmulas culturales, sociales y religiosas, las cuales habían remitido - de manera parcial, por decir lo menos - a la mujer a un estadio de desprecio y sospecha de malignidad. De tal manera que muchas de sus expresiones sean implícitamente agresivas e injustas a nuestros ojos.

Nada más revelador respecto al peso de los significados en el problema que la propia definición del vocablo «bruja» en el siglo XvI, cuando Martín de Castañega afirma el pacto diabólico expreso como la condición previa para la denominación de bruja: «E este nonbre, bruxa, es vocablo italiano que quiere dezir quemado o quemada, porque la pena de los semejantes sortílegos y magos era que los quemavan y assí les quedo tal nombre» (1994: 19). Luego, en el siglo XVII: «Ha se de advertir, que, aunque hombres han dado, y dan en este vicio y maldad, son más ordinarias las mujeres, por la ligereza y la fragilidad, por la lujuria y por el espíritu vengativo que en ellas suele reinar; y es más ordinario tratar esta materia debajo del nombre de bruja que de brujo» (Covarrubias Orozco 1611: f. 154r). Y un siglo más tarde: «BRUXA. Comunmente se llama la muger perversa, que se empléa en hacer hechizos y otras maldádes, con pacto con el demónio, y se cree, ù dice que vuela de noche. Díxose assi por analogía de la Bruxa ave nocturna. Lat. Venefica. Saga. Stri $\rangle^{6}$ (Diccionario de Autoridades 1726, t. I).

Los autores de tratados demonológicos, en tanto redactores autorizados de textos especializados y doctrinales con afán correctivo, recogieron, ampliaron y difundieron las percepciones negativas entre la mujer y la definición del concepto de la bruja, principalmente como operadora irredenta del mal diabólico: «LAS BRUJAS, esa progenie de víboras del infierno, no sólo inflaman las almas mediante sus obras diabólicas, sino que incendian cuerpos, casas, y ciudades enteras; por lo cual manifiestamente son combustible para el fuego eterno» (Guazzo 1988: 169). Al tiempo que robustecieron la imagen de la mujer débil, sola y aislada como víctima propicia, mediante un tono de desprecio:

Para Gerolamo Cardano las brujas eran viejas miserables y mendigas que vivían en el campo alimentándose de castañas y hierbas. Para Nicolás Remy eran «mendigas, capaces de vivir sólo con las limosnas».

Para Johann Weyer las brujas eran «pobres criaturas ignorantes, viejas y carentes de poderes» (Centini 2002: 30).

6 En este caso, por tratarse de la definición del vocablo en el Diccionario de Autoridades a la voz «bruxa», no se ha actualizado la ortografía. 
Dada la opinión común respecto al tono misógino del discurso en cuestión, cabe preguntarse si esta percepción contemporánea define correctamente las declaraciones alrededor de la mujer en el discurso demonológico, para lo cual es preciso saber en qué medida sus calificaciones refieren un intento de resolver el dilema de la supuesta mujer maligna y cuándo corresponden al campo semántico de la magia tenida por verdad atemorizadora. Y, finalmente, hace falta reconocer los rasgos significativos de los dictámenes acerca de las mujeres, ya sea como enemigas de la religión y acólitas del mal, como personas simples engañadas por un poder superior, o como personas de fe partícipes de una religión amenazada, en el contexto del discurso demonológico.

El Canon episcopi, considerado uno de los documentos oficiales fundantes de la conexión entre la mujer y la brujería ${ }^{7}$, afirma que debe reprobarse la creencia de algunas mujeres que creen viajar durante la noche, por los aires, sobre los lomos de algunas bestias y en compañía de la diosa pagana Diana. Aunque describe el vuelo nocturno como un acto de mujeres, pide desterrar de las diócesis a cualquier hombre o mujer que sigan hechicerías y maleficios (Hope Robbins 1991: 172-173).

En este caso, independientemente de la polémica acerca de la autenticidad del canon y la reconvención en materia de credulidad de la brujería que operará al seno de los dictámenes católicos, el documento vincula a la mujer con la creencia de volar, pero remite todo a la imaginación. Por otro lado, no menciona que se dirija al aquelarre, como se relatará siglos adelante. La lógica del mito, ya en plena época de la brujomanía, señala que la brujería es esencialmente cuestión de mujeres perversas: ellas se untan el misterioso ungüento para volar, cruzan el cielo sobre lomos de animales y van al aquelarre a adorar a Satán.

Sin embargo, esta acusación no necesariamente inició con el énfasis sexista que la idea común supone: efectivamente el mito del aquelarre en general culpa a las mujeres de asistir al aquelarre, pero esto depende del demonólogo o tratadista y del momento histórico que se trate. Al menos en el inicio de la construcción del mito, es decir, en plena manifestación del Renacimiento ${ }^{8}$, la relación aquelarre y hombre es general y neutra, no especifica ni responsabiliza a las mujeres. Una de las primeras descripciones del sabbat, conventículo o aquelarre, de alrededor

$7 \quad$ De acuerdo a Hope Robbins (1991: 171) este canon fue atribuido erróneamente al Concilio Ancirano del año 314, supuestamente fue redactado por Reginon de Prüm, abad de Tréveris, alrededor de 906, y luego se sumó con modificaciones al Corpus Juris Canonici, de Graciano de Bolonia, durante el siglo XII. Por otro lado, su original ha sido cuestionado, pues se ha tachado de apócrifo. El ilustrado benedictino fray Gerónimo Feijoo en su discurso «Uso de la Mágica» del Teatro crítico universal, dudó de su autenticidad.

8 De acuerdo a la mayoría de los investigadores, la idea de que la brujería era un crimen grave y por lo tanto debería perseguirse a los brujos y las brujas, proviene del Renacimiento (Stephens 2003: 125). 
de 1460, comienza afirmando: «Cuando los acusados querían ir a la citada Vaulderie [sic] untaban una varita de madera, así como sus manos y sus pies, con un ungüento que el Diablo les entregaba, y después se ponían esta varita entre las piernas y volaban a donde querían ir» (Villeneuve 1970: 287).

No obstante provenir de una fuente heredera de las mismas influencias discriminadoras, como cualquier otra de su tiempo (a saber: las Memoires de $J$. du Clerq) este opúsculo no distingue entre brujos y brujas, ni establece a la figura de la mujer como la principal protagonista del aquelarre o vauderie ${ }^{9}$.

El discurso sufre un cambio radical de la mano de los redactores del Malleus maleficarum. Amparados en los permisos jerárquicos y su denuedo contra la herejía diabólica, los frailes dominicos Kramer y Sprenger, recorrieron varias regiones centroeuropeas comprometidos en una campaña de localización, identificación, castigo de la hechicería y todo lo que oliera a superstición o desvío doctrinal. En ocasiones se olvida que el libro contiene una parte práctica que le antecede y de la cual se conoce poco; que su especulación demonológica proviene de una campaña bélica, considerada real y necesaria, contra los delitos promovidos por los demonios, según los propios afectados. Necesariamente, los embustes, las ignorancias y los rencores sociales acerca de las mujeres debieron combinarse con los propios dogmas de predilección masculina que los inquisidores aprendieron durante su preparación sacerdotal. Es decir, los dominicos no inventaron la misoginia alrededor de la mujer considerada bruja a fin de revelarla en su libro, sino que acentuaron la presencia social de la brujería, denunciaron los peligros de su existencia (mismos que ahora sabemos ficticios) consolidaron el marco jurídico para su extirpación y, finalmente, lo expresaron en términos inadmisibles hoy, evidentemente misóginos.

En uno de los apartados más inquietantes acerca del asunto, «Pregunta VI. Acerca de las brujas que copulan con los demonios. Por qué las mujeres son las principales adeptas a las malvadas supercherías» (2016: 113-125), Kramer y Sprenger intentan responder a varias cuestiones específicas para descubrir cómo funciona la vinculación de las mujeres con los demonios. El punto de partida está cargado de fantasía sexual, pues creen que, de algún modo, los demonios copulan con algunas mujeres, pero se preguntan de qué está compuesto el cuerpo que el demonio adopta para el efecto, cómo se trasvasa el semen, cuándo y dónde acontece el ayuntamiento carnal, y si alguien puede verlo (2016: 113-114). Dado que ese contacto representa uno de los puntos execrables del mito de la brujería, les preocupa

La traducción al español del libro consultado anota «Vaulderie». Más propiamente, el vocablo es «vauderie», que refiere a una asamblea de herejes o hechiceros. El mismo Villeneuve la define: «Vauderie (ou Vaudoiserie): Terme qui à partir du $\mathrm{Xv}^{\mathrm{e}}$ siècle devint synonyme de Sabbat» (1998: 1.010). 
sobremanera analizarlo, así que dedicarán el capítulo IV de su texto a describirlo; pero antes de establecer la dinámica erótica supranatural, tratan de exponer lo que consideran es la identidad perversa femenina a través de cuestionamientos. La duda inquisitorial consiste en saber, primero, «[...] por qué estas aberraciones se producen en este sexo, tan frágil, antes que en los hombres» (2016: 114), y qué tipo de mujeres realizan tales actividades, en cuyo caso destacan la malignidad de las parteras. Mediante estas preguntas repiten la idea común de la debilidad femenina, tomando como punto de referencia el modelo deseable, o sea, el hombre. Se trata de una equiparación constante e inequitativa en este tipo de discurso:

Un ejemplo que no necesita comentarios nos llega de Laurent Joubert, «consejero y médico ordinario del rey (Enrique III), doctor de corte, canciller y juez de la universidad de medicina de Montpellier», que en su libro Errores populares (1578) afirmaba: «El varón es más digno, excelente y perfecto que la mujer», la cual «es como un defecto cuando no se puede hacer mejor» (Centini 2002: 30-31).

Resalta también la inquina contra el oficio de las parteras, quienes serán uno de los blancos predilectos de los inquisidores. A tal grado que el mito se enriqueció con el episodio de los niños asesinados, robados o encomendados al diablo justo en el momento de nacer, a instancias de algunas comadronas o parteras, señaladas como brujas.

La respuesta a tales dudas se inicia con una aclaración parcialmente equilibrante, aunque reductora: «Y, sin menoscabar en modo alguno un sexo en el que Dios siempre ha hallado gran gloria por el hecho de que Su poderío pudiera difundirse» (2016: 114). Si bien antes de enumerar los defectos de las mujeres, los autores intentan la disculpa, suavizando con ello las asperezas que vendrán, resulta revelador que la valoración de las mujeres ante Dios se sitúe, primero, en el servicio que ellas puedan prestar al dominio divino y, segundo, en la función reproductora que, supuestamente, aumenta la grey católica.

El discurso impersonal se canaliza hacia un receptor específico: los inquisidores explican la cercanía entre mujer y brujería "para admonición de las mujeres» (2016: 114). Este sesgo interlocutivo aparece en varios de los textos del corpus demonológico. Los eruditos intentan aleccionar a las mujeres. En teoría tratan de ubicarlas como las destinatarias de sus dictámenes; aunque, en la realidad, la oratoria doctrinal llegaba al creyente siempre de forma indirecta, a través de intermediarios autorizados: confesores, guías espirituales, exégetas y tutores. La religión católica siempre ha resaltado el papel de la intercesión doctrinal.

La lista de defectos femeninos que, según el Malleus, responden al porqué de su falibilidad extrema, se inicia con la incapacidad de moderarse a sí misma y a la lengua. Continúa con los dichos, máximas y sentencias que padres y textos de la Iglesia han legado y que refieren cierto carácter maligno en la mujer. Mediando 
referencias al evangelio de san Mateo y la opinión de Juan Crisóstomo, los dominicos insertan una exclamación: «qqué otra cosa es una mujer sino un enemigo de la amistad, un castigo ineludible, un mal necesario, una tentación natural, una calamidad, un peligro doméstico, un deleitable detrimento, un mal de la naturaleza pintado con colores!» (2016: 116). La elocución del libro suma más supuestas razones del vínculo predicho: la envidia, siguiendo a Cicerón; el engaño, la premeditación y la ira vengativa, de acuerdo a Séneca; la credulidad y el odio, citando el Eclesiástico; la escasa o nula inteligencia, refiriendo a Terencio y Lactancio; la premeditación del mal, interpretando una frase de Catón, etc.

Pero la razón natural reside en que es más carnal que el hombre, como se ve en sus abominaciones carnales. Y debe notarse que hubo un defecto en la formación de la primera mujer, porque fue formada de una costilla curva, es decir, de una costilla del pecho que se halla torcida, por decirlo así, en dirección contraria a la de un hombre. $\mathrm{Y}$ a causa de este defecto es un animal imperfecto, siempre traiciona (2016: 118).

En este caso, un mito explica a otro. La noción de mujer como animal imperfecto cruzó la cultura occidental y sirvió de base para la marginación, el desprecio y la satanización del género. Para reforzar esta imperfección de origen, los autores dominicos repiten la etimología de la palabra y la esgrimen como argumento: «Y todo ello se demuestra por la etimología del nombre, pues fémina proviene de $f e$ y minus, débil para mantener y conservar la fe» (2016: 119). El prejuicio procura abarcar tanto al funcionamiento y uso del cuerpo femenino como a los rasgos del carácter: mente, voluntad y fisonomía quedan en entredicho. La mujer no solo tiene una débil constitución física y mental, sino que además prefiere el error, el pecado, el mal: «Luego, una mujer malvada está naturalmente más pronta para vacilar en su fe y, por consiguiente, para abjurar de la fe, lo cual constituye el núcleo de la brujería» (2016: 119).

Es notorio que los epítetos, calificaciones y prejuicios enumerados antes pueden ser trasladados fácilmente al terreno de la malignidad aplicando el código moral calificador del pecado en el catolicismo, hasta compaginar un concepto por otro, es decir, la idea de mujer con la idea de bruja; a tal grado que parezcan injustos y marginadores a la opinión actual que las reconoce habiendo detectado el doble juego discriminador de la cultura occidental en el que se feminiza al mal a la vez que se maligniza a la mujer. Así que cada frase calificadora encaja en las descripciones acusadoras contra la bruja, tanto en los manuales inquisitoriales como en los tratados contra la magia. La mujer se identifica bruja y la bruja necesariamente tiene forma de mujer.

Casi de improviso, los autores insertan breves excursos de reconocimiento y alabanza - inesperados para el lector que atiende a la crítica misógina del texto-, 
y así matizan un poco la pintura negativa: «Sin embargo, para las buenas mujeres también hay elogios, como cuando leemos que han dado beatitud a los hombres y salvado reinos, países y ciudades, como Judith, Deborah y Esther» (2016: 117). Las ideas reivindicativas son: primero, como se citó antes, Dios halla gloria en las mujeres porque gracias a ellas se difunde su poder (2016: 114); segundo, varias frases de libros de la Biblia (Corintios, Eclesiástico y Proverbios) ponderan a la mujer virtuosa; tercero, en el Nuevo Testamento se admira la virginidad, la santidad y la fe de las mujeres (2016: 117); y cuarto, si bien en el Antiguo Testamento se habla mal de las mujeres debido al pecado original de Eva ${ }^{10}$, en el Nuevo ese error se ve redimido por María. «Por ello los predicadores deberían alabarlas tanto como fuere posible» (2016: 118).

A pesar de anotar los anteriores puntos de reconocimiento a las mujeres, siempre y cuando estas sean cristianas y virtuosas, el Malleus regresa a la convicción de que la relación entre la brujería y el sexo femenino es fuerte y constante, dada su constitución débil, según lo demuestran la razón y la experiencia:

Pero como en nuestros tiempos la brujería se encuentra con más frecuencia entre las mujeres que entre los hombres, como sabemos por experiencia, si alguien siente curiosidad en cuanto a la razón, podemos añadir a lo dicho lo siguiente; que a causa de su debilidad de mente y de cuerpo no resulta extraño que caigan en mayor medida bajo el hechizo de la brujería (2016: 118).

Suele adjudicarse al Malleus maleficarum la instalación cimentadora de las ideas acusatorias de maldad hacia la mujer, de acuerdo a la cita anterior, hay cierta razón en esa crítica, efectivamente el tono lapidario e intransigente del libro merece una discusión amplia, pero en realidad, como ya se dijo, las ideas al respecto habían madurado a través de un sistema religioso patriarcal y un liderazgo masculino que excluía, de facto, toda participación femenina, a tal grado que fue necesario justificar la falta de presencia de las mujeres en la toma de decisiones sociales y religiosas que afectaban a todos mediante un discurso autoritario, unilateral y excluyente; todo esto requirió un tácito desprecio y ninguneo en cuanto a su capacidad intelectual y física. El libro de los dominicos es una pieza más en esta tradición discursiva, pero, eso sí, es una pieza importante debido a su gran influencia social, merced a las múltiples ediciones, lecturas, interpretaciones, glosas, citaciones y ampliaciones que ocurrieron en consecuencia de sus dictámenes.

El discurso erudito acerca de la magia, la brujería y la demonología mantuvo un sorprendente ritmo editorial, así que los supuestos alrededor de la falibilidad

10 Remitiendo a san Jerónimo, los autores reiteran el juego palindrómico entre Eva y Ave, como principio y fin del pecado. Una atiende a la provocación de la serpiente edénica, escucha al mal, y la otra le pisa la cabeza, acaba con el mal. 
femenina continuaron difundiéndose y, como muchos investigadores hemos afirmado, alimentando, inventando y autorizando mitos y prejuicios populares.

La lista de errores adjudicados a las mujeres servidoras del mal, salvo algunas variantes, se repite en los textos doctrinales del catolicismo como una receta de enunciados afirmativos. A saber: exclusión del sacerdocio cristiano, propensión al engaño diabólico, herencia de Eva, curiosidad, carencias intelectuales, charlatanería, descreimiento, tendencia a la ira y a la venganza, etc. Las secuencias de prejuicios aparecen sintetizadas o comentadas durante la época de la brujomanía, y un poco más allá, por herederos y voceros de una explicación que no admite réplica, análisis o mucho menos corrección.

[...] y por la mayor parte son viejas y feas las brujas, y hay más mujeres que hombres de estas ministras del diablo, porque como la Iglesia las tiene apartadas de la administración de sus sacramentos, por eso el demonio las da autoridad para sus embelecos, y porque con más facilidad las engañará a ellas, como pareció en la primera mujer que fue Eva. A más de que son demasiado curiosas en saber vidas ajenas (aunque no sean de santos) y en escudriñar cosas ocultas, deseando saber cosas particulares, y como tienen poca capacidad, el demonio luego las entiende. También porque son muy parleras, más que los hombres, y no guardando secreto unas a otras, luego, aunque sea malo desear saber, y así las engaña con facilidad, por falta de verdadera fe y de constancia, que la tienen harto poca en lo bueno, y últimamente porque son más iracundas y más vengativas que los hombres, y como tienen menos fuerzas para vengarse, procuran el favor del demonio (Ardevines Isla 1621: f. $100 \mathrm{r}-\mathrm{v})^{11}$.

La continuidad de las ideas, polémicas y opiniones alrededor de la brujería tiene matices interesantes ${ }^{12}$. Por ejemplo, no a todos los censores les interesó explicar la feminidad como un grave disturbio promotor del demonio. Considérense dos casos de autores importantes: Pedro Ciruelo y Martín del Río.

En el primer tercio del siglo $\mathrm{XvI}^{13}$ el llamado «maestro Ciruelo» dio a conocer su Reprobación de las supersticiones y hechicerías, un hito del tema en el ámbito hispánico. Contrario a la tendencia discriminante del discurso contra las

11 Solo en este caso de cita textual de edición antigua, a fin de hacerla más legible, se actualizaron la ortografía, las grafías y la puntuación.

12 Por ejemplo, Martín del Río censura constantemente la opinión de Johann Wier, autor del libro De praestigiis daemonum, de 1563, lo llama abogado de brujas, impío, calvinista y hereje. Por cierto, Wier no fue el único letrado que aconsejó mesura frente al fenómeno de la brujería. Friedrich von Spee, hizo otro tanto en su tratado Cautio criminalis, sive de processu contra sagas, de 1631. En las antípodas del escepticismo ideológico se encuentra Giulio Cesare Vanini, quien, debido a su incredulidad en estos temas, fue condenado a muerte en 1619.

13 La primera edición conservada data de 1530, hecha en Alcalá. 
supersticiones, la carga diferenciadora contra la mujer no aparece en su trabajo mediante la forma de una denuncia directa. Ciruelo discute y efectivamente reprueba, todo tipo de supersticiones conocidas y practicadas en su época, sin diferenciar la credulidad, sin señalar a un culpable especial, sea por género, raza o religión. En todo caso, el culpable señalado es el diablo: «Desta cruel malicia y enemistad perpetua que los diablos tienen a los hombres, nos avisó Dios al principio del mundo, después que con su tentación el diablo hizo pecar a la primera mujer, porque estemos con recelo dél y no vivamos descuidados» (2005: 23). En general, Ciruelo habla de personas que pretenden obtener beneficios a través de medios ilícitos. Señal inequívoca de que lo que le importa son los hechos, es decir, censurar aquello que considera dañino para la fe, los errores, las deviaciones del dogma, no satanizar a sujetos particulares: «A esta nigromancia pertenece el arte que el diablo ha enseñado a las bruxas o xorguinas, hombres o mujeres, que tienen hecho pacto con el diablo, que untándose con ciertos ungüentos y diciendo ciertas palabras, van de noche por los aires y caminan lexos a tierras a hacer ciertos maleficios» (2005: 36). El autor nunca establece que la mayoría de las personas que practican hechicería o brujería sean mujeres, ni que ellas sean proclives al mal, lo cual marca una pausa refrescante en la continuidad de tal acusación. Incluso, indirectamente y sin intención, ayuda a cuestionar al prejuicio que liga a la mujer con el mal, pues recuerda que Dios le dijo al diablo que pondría enemistad entre él y la mujer. Ciruelo interpreta parte del Génesis como una gran advertencia divina para que el hombre jamás preste oídos al mal, ni amiste o acuerde con el diablo, puesto que él es el enemigo (2005: 23). Aunque, por supuesto, su discurso no es neutro, repetidamente se nota la carga ideológica de género: «También las cosas que hacen las bruxas o xorguinas son tan maravillosas, que no se puede dar razón dellas por causas naturales» (2005: 22).

En este mismo tenor, Martín del Río representa un caso especial en el asunto. Pródigo en citas, ejemplos y referencias a autoridades clásicas de la tradición grecolatina y la patrística, su credulidad y preocupación ante la relación de hombres y demonios choca ante su fama de hombre con alta capacidad intelectual y sabiduría. Su obra, Disquisitionum magicarum libri sex ${ }^{14}$, atacó a dos tipos de enemigos: a los hombres cuya opinión, creencias o actividades contravinieron de alguna manera a la Iglesia y a los demonios, cuya ira contra Dios, presencia terrenal y funcionamiento entre las personas malvadas, ingenuas o desprevenidas cree constantes, reales e innegables. Incluye en la primera categoría a herejes, magos, maléficos, brujas, lamias, nigrománticos, judíos, apóstatas, asesinos, energúmenos,

\footnotetext{
14 Tuve a la vista la edición latina de 1608, publicada en Lugduni, pero utilicé la traducción del libro II hecha por Jesús Moya en 1991. La primera edición se ubica justo en el cambio de siglo: 1599 y 1600
} 
supersticiosos, adivinos, astrólogos y una amplia gama de oficiantes de prácticas mágicas que, desde su punto de vista, desobedecían las leyes divinas o perjudicaban el adecuado funcionamiento de la religión.

Del Río no es especialmente difamador del género femenino, al menos no más que el resto de teólogos cuyo centro de atención se ubica más en los hechos transgresores y las intrigas diabólicas entre los hombres que en los sujetos. Aspecto que comparte con Pedro Ciruelo. Reproduce una gran cantidad de casos extraordinarios, que refuta, corrige o da por verdaderos, en los cuales las mujeres aparecen como protagonistas, desde alguna esposa que haya dado a luz a un ser monstruoso hasta la bruja que hechiza a sus enemigos, pero no dedica un apartado de su extensa obra para denostar la identidad de las mujeres y argumentar el porqué ellas, en particular, son proclives al mal diabólico. Eso sí, su creencia en brujerías, aquelarres, pactos diabólicos y toda serie de amenazas demoniacas es contundente.

Contemporáneo de Pedro Ciruelo y autor de una obra similar, fray Martín de Castañega sí incluye un capítulo para explicar la presencia mayoritaria de la mujer en las oscuras artes mágicas. Los aspectos que señala lo relacionan con una lectura previa: todo indica que Castañega leyó el Malleus maleficarum o a alguno de sus comentaristas. Bien los señala uno de los actuales editores de su obra: «Por otro lado, parte de las raíces de la acendrada misoginia que rezuma la obra, puede achacarse a la influencia del Malleus, sin descartar por supuesto la lectura de algunos otros autores comentados» (Muro Abad 1994: XXXVI). También es posible que la continuidad de la tradición prejuiciosa haya sido tan fuerte que estuviera ya imbricada en los procesos educativos por los que atravesaban los frailes seculares y regulares.

El breve capítulo quinto «Porque destos ministros diabolicos ay mas mugeres que hombres» del Tratado de las supersticiones y hechicerías contiene interesantes aspectos para entender la continuidad de la relación entre la mujer y la bruja ${ }^{15}$. Más que hacer un esfuerzo por explicar los motivos, debilidades o carencias de las mujeres para convertirse en acólitas de Lucifer, o sea, los de aquellas relacionadas con la brujería, el autor las clasifica enumerando sus fallos o errores directamente, de acuerdo a los dictámenes desfavorecedores.

A su juicio, entonces, hay más mujeres que hombres entre los ministros del diablo porque, primero, ellas han sido apartadas de las labores religiosas, así que el demonio, siempre con el afán de remedar y parodiar las ceremonias cristianas,

15 En la Nueva España, fray Andrés de Olmos redactará en náhuatl una versión del tratado de Castañega, el Tratado de hechicerías y sortilegios, datado en 1553, adaptando y enfocando el intento doctrinal para las circunstancias especiales que presentaba la evangelización de México. El capítulo en cuestión, salvo la aplicación y el cambio de destinatario y de tipología femenina acusada (para el caso, la indígena) presenta el mismo contenido. 
les confía la administración de su iglesia negra, una iglesia en la cual cada acto imita sacrílegamente a los ritos oficiales ${ }^{16}$. Segundo, son fáciles de engañar debido a la herencia de Eva, la primera engañada; tercero, son más curiosas por naturaleza y desean obtener conocimientos ocultos; cuarto, son charlatanas e incapaces de guardar secretos, así que comunican una a otra sus inquietudes; quinto, son iracundas y vengativas, pero débiles, por lo tanto piden al demonio que les ayude; y sexto, mientras que a los hombres que saben realizar actos hechiceros gracias a poseer algún conocimiento arcano se les llama nigrománticos, a las mujeres, dado su desconocimiento de artes y ciencias no se les puede llamar nigrománticas, sino brujas o alguna variable. Este último aspecto obliga a una reconexión entre la realidad de la magia al seno de la sociedad y la diferenciación de género que el oficio implica. Efectivamente, gracias a la exigencia de reconocimiento de algunos filósofos renacentistas, la denominación social relacionada al saber oculto hace de un hombre con conocimientos herméticos un mago, un nigromántico, un sabio, en última instancia; en cambio, convierte a la mujer en posesión de similares bagajes ocultos, en una bruja, sorguina u otros términos despectivos. En ambos casos, la conexión diabólica se debe a un pacto expreso, no a ciencias ni artes (Castañega 1994: 20-21).

Finalmente, el autor considera que también la mujer recurre al demonio antecediendo o su concupiscencia o su avaricia. Indica que las mujeres traban amistad con el demonio más fácilmente si son viejas y pobres; pues siendo ya viejas los hombres no las buscan para saciar sus apetitos carnales, y si son pobres no se conforman con su destino y esperan obtener riquezas del diablo, vanamente, pues las engaña (1994: 21). En ambos casos, el aspecto que se reprueba consiste en la supuesta insaciabilidad sexual de las mujeres. Desde esta perspectiva, el cuerpo femenino exige atención erótica y la busca mediante la lozanía de la juventud o la compra de favores. Ser joven o ser rica garantizaría a cualquier mujer continuar gozando de las caricias de los hombres. En este autor y en la mayoría de los demonólogos el factor erótico es de suma importancia, a tal grado que en la mayoría de tratados, directa o indirectamente, se reitera la convicción de una tendencia maligna del uso del cuerpo, en especial el de la mujer, mediante la relación de episodios descriptivos o sugerentes de una desenfrenada e indiscriminada actividad sexual, claramente fantástica y reveladora de la necesidad de desahogo erótico social.

La obra de Pierre de Lancre, Tableau de l'inconstance des mauvais anges et demons, esencial en la historia de la brujería, ofrece algunos visos de inconsciente

16 El autor los llama «execramentos». Algunos otros tratadistas e inquisidores también usaron el concepto. Se trata de los ritos sacramentales de la liturgia católica, pero efectuados por los seguidores de la secta de los brujos para adorar a Satán. Es posible ver en esto un antecedente de la inversión de la eucaristía que luego constituyó la dramática misa negra. 
ambigüedad frente a la mujer ${ }^{17}$. Por un lado, al describir algunas costumbres locales, el autor parece seducido momentáneamente por la belleza y actitud festiva de las mujeres del País Vasco; por otro, como sus correligionarios, es un crédulo acusador, un férreo inquisidor que intenta explicar por qué las mujeres devienen en brujas y afirma que son mayoría en la práctica de hechicerías y en la asistencia al aquelarre. De inicio, esta búsqueda de explicaciones le inspira un parangón:

[...] las mujeres sólo comen manzanas, sólo beben jugo de manzanas, lo cual les proporciona la ocasión para que muerdan con agrado esta manzana prohibida, que hizo propasarse y quebrantar la prohibición del mandamiento de Dios a nuestro primer padre. Son Evas que seducen de buena gana a los hijos de Adán y, privadas de cerebro, viven en las montañas en absoluta libertad y simpleza, como Eva en el paraíso terrenal. Escuchan a hombres y demonios, prestando atención a cuantas serpientes las quieran seducir (Lancre 2013: 45).

Lancre da la impresión de ser un asombrado extranjero recorriendo la comarca de Euskal Herria, específicamente Laburdi, donde todos los habitantes son brujos o saben algo al respecto. Sin embargo, su tránsito por el País Vasco distó de ser inocuo: tras de sí dejó una estela de acusaciones, torturas y muertes, cercana al genocidio. Tal era su empeño por exterminar a los brujos que se hizo acompañar de una detectora de brujas, una jovencita que supuestamente reconocía en el cuerpo de las sospechosas la stigma diaboli o marca del diablo. De tal suerte que se erigió en uno de los constructores y ampliadores del mito de la brujería, porque, gracias a su texto, a caballo entre la crónica y el tratado, resulta claro que interpretó muchas costumbres locales y tradiciones folclóricas como ritos mágico-diabólicos, e inoculó en las comunidades que visitó y asoló las estructuras semánticas propias de la brujería. Con él, muchas personas procesadas aprendieron qué era un aquelarre cargado de sentido diabólico. Mujeres que nunca antes habían considerado que su asistencia a las fiestas fueran motivo de escándalo, infidencia, apostasía o pacto con el diablo, fueron inducidas a aprender el mito de la brujería y narrar sus festejos como si fueran orgías diabólicas. Y, por supuesto, la diferenciación tendenciosa entre el bien y el mal que adjudica a un género los errores más graves de la conducta humana, según el mito de la brujería, sumó una voz más, la que, a semejanza de Kramer y Sprenger, combina la práctica inquisitorial de campo con la teoría demonológica.

Lancre dedica el «Discurso III. El porqué hay más mujeres brujas que hombres, y de cierta clase de mujeres, llamadas benedictas, que en el país de Laburdi tienen como sacristanas» (2013: 51-56) a afirmar las consabidas características

17 Tengo a la mano una versión electrónica de la edición francesa de 1613, pero he utilizado la traducción al idioma castellano, específicamente la tercera edición, del año 2013. 
negativas de las mujeres que las acercan por necesidad al servicio de Lucifer. Las críticas son más o menos semejantes a las ya referidas por los demás letrados, habida cuenta de que le basta aseverar que está demostrado que «[...] la mujer tiene más inclinación natural a la brujería que el hombre, siendo ésta la razón por la que hay más mujeres brujas que hombres, y aunque el motivo para que eso sea así quizás sea un secreto divino, sí podemos emitir aquí alguna razón probable» (2013: 51-52). Para este inquisidor la naturaleza proclive a la desmesura, la falta de control del cuerpo, el imperio de los sentidos, la animalidad desbocada e inevitable de la mujer constituyen las razones esenciales de su papel de bruja y, en especial, de su asistencia gustosa al aquelarre, el acontecimiento esencial que más le preocupa y tiene por real en todos sus aspectos, escenas y maldades que ahora se califican de fantasías misóginas. Así lo sintetiza:

La causa sería más bien la fuerza de la avidez salvaje que empuja y reduce a la mujer a excesos, a los que se entrega de buena gana para gozar de sus apetitos, para vengarse o para conocer otras novedades y curiosidades que se ven en dichas asambleas. Todo lo cual ha movido a algunos filósofos a clasificar a la mujer entre el hombre y la bestia bruta (2013: 52).

El silogismo se enuncia solo: el mal se revela a través de la imperfección; la mujer es imperfecta, ergo la mujer es propensa al mal. Por lo tanto, sobre el discurso censor de la magia prevalece la preocupación de la presencia del mal preternatural entre los hombres. Los agentes activos de esa amenaza son los brujos, de los cuales sobresalen en cantidad y peligrosidad las brujas, pues antes que sirvientes de los demonios son mujeres, es decir, seres imperfectos en los cuales el mal anida o al menos son susceptibles de su asalto y posible convencimiento. Describir este esquema condujo a los demonólogos a marginar y acusar a las mujeres mediante supuestos argumentos y calificaciones, lo que a la luz de la búsqueda actual por alcanzar la igualdad de género sugiere un alto grado de enjuiciamiento misógino; muy a pesar de que varios de los letrados tuvieron en mente más esclarecer el problema que entender a los individuos. Es decir, su diatriba ataca al mal diabólico y a la maldad humana, no a los sujetos, aunque estos encarnen al mal o le sirvan conscientemente de instrumento.

La dificultad de la vinculación del mal en la mujer conduce a una paradoja insalvable, pues, aunque el enemigo y objetivo final sea el diablo, las actividades de la brujería tienen un vehículo identificable a través de la experiencia y el propio discurso - fantástico para la actualidad, real y preocupante según ellos-, ese operador de las intrigas demoniacas es la bruja, una enemiga peligrosa, una mujer que ha renunciado a lo bueno y correcto para abrazar la causa de los rebeldes y sobre cuyo cuerpo necesariamente debe aplicarse el escarmiento, sin miramientos ni complejos de culpa, toda vez que para el sistema religioso lo importante no es 
la materia, sino el ánima. Una mujer que además está siendo engañada por aquellas entidades metafísicas que la cooptaron. La bruja vive y muere en el error justo por ser primero mujer, debido a sus carencias e imperfecciones consideradas naturales por un sistema ideológico que así la define, o guarda silencio cuando se ve incapaz de reconocer su identidad: «Muchas cosas se pudieran decir de esta palabra, pero otros las dicen, y con más libertad de lo que sería razón» (Covarrubias Orozco 1611: f. 558r) ${ }^{18}$.

18 Respecto al vocablo «mujer», Centini cita el libro La Somme des pechez en su primera edición de 1584 para indicar la manera como se interpretaba la palabra latina mulier, mediante un acróstico revelador de varios prejuicios negativos: «M: la mujer malvada es el mal de los males; U: la vanidad de las vanidades; L: la lujuria de las lujurias; I: la ira, la cólera de las cóleras; E: la furia de las furias (alusión a Erinia); R: la ruina de los reinos» (Centini 2002: 29). Tuve a la vista y revisé dos ediciones del tratado, la de 1587 (París, por Arnold Sittart) y la de 1599 (Tournon, por Claude Michel) y no encontré este párrafo. Sin embargo, a menos que sea un error de referencia de Centini, sí debe aparecer en la edición de 1584. 


\section{BiBLIOGRAFÍA}

Aquino, santo Tomás de (2005). Suma de Teología IV. Parte II-II 8b. Madrid: Biblioteca de Autores Cristianos.

Ardevines Isla, Salvador (1621). Fábrica universal y admirable de la composición del mundo mayor, a donde se trata desde Dios hasta nada y del menor, que es el hombre. Madrid: Diego Flamenco.

CASTAÑEga, fray Martín de (1994). Tratado de las supersticiones y hechizerias y de la posibilidad y remedio dellas (1529). Juan Roberto Muro Abad (ed.). Logroño: Instituto de Estudios Riojanos.

Centini, Massimo (2002). Las brujas en el mundo. Barcelona: De Vecchi.

Ciruelo, Pedro (2005). Reprobación de las supersticiones y hechicerías. Valladolid: Maxtor.

Covarrubias Orozco, Sebastián de (1611). Tesoro de la lengua castellana o española. Madrid: Luis Sánchez.

Diccionario de Autoridades (1726) < http://web.frl.es/DA.html > [Consulta: 01/03/2019].

Guazzo, Francesco Maria (1988). Compendium maleficarum. Isaac Pradel Leal (trad.). Alicante: Editorial Club Universitario.

Hope Robbins, Rossell (1991). Enciclopedia de la brujería y demonología. Madrid: Debate.

Kramer, Heinrich y Jacobs Sprenger (2016). Malleus maleficarum o El martillo de los brujos. Barcelona: Iberlibro.

Lancre, Pierre (2013). Tratado de brujería vasca. Descripción de la inconstancia de los malos ángeles y demonios. Elena Barberena (trad.). Tafalla: Txalaparta.

Olmos, fray Andrés de (1990). Tratado de hechicerías y sortilegios, 1553. Georges Baudot (ed.). Ciudad de México: Universidad Nacional Autónoma de México.

OrTIz, Alberto (2015). El aquelarre. Mito, literatura y maravilla. Barcelona: Oblicuas.

Río, Martín del (1991). La magia demoníaca. Jesús Moya (trad.). Madrid: Hiperión.

Villeneuve, Roland (1970). El universo diabólico. Madrid: Felmar.

Villeneuve, Roland (1998). Dictionnaire du diable. Paris: Omnibus.

Zamora Calvo, María Jesús (2016). Artes maleficorum. Brujas, magos y demonios en el Siglo de Oro. Barcelona: Calambur Editorial.

Recibido: 05/04/2019

Aceptado: 20/05/2019 
LA COMPRENSIÓN MÁGICA DE LA FEMINIDAD.

OPINIONES DEMONOLÓGICAS ACERCA DE LAS MUJERES Y LAS BRUJAS

RESUMEN: La opinión común actual ha señalado y reprobado la contundente misoginia de la idea tradicional que malignizó a ciertas mujeres en momentos críticos de los siglos pasados, calificándolas de brujas y de enemigas conspiradoras contra la fe cristiana mediante un pacto diabólico y fantásticas actividades transgresoras, como el vuelo nocturno y la asistencia a los aquelarres. En esta construcción ideológica y social los tratados en contra de la magia y las supersticiones colaboraron directamente. Con todo, todavía falta análisis y discusión respecto a la manera en que los tratados demonológicos vincularon a la mujer con las prácticas mágicas y cómo se reprodujo ese dictamen a través de distintos textos dedicados a controlar, en lo posible, toda tendencia heterodoxa.

PALABRAS ClaVE: mujeres, brujas, censura, inquisidores, demonología.

\section{THE MAGICAL UNDERSTANDING OF FEMINITY. DEMONOLOGICAL OPINIONS ABOUT WOMEN AND WITCHES}

ABSTRACT: The current common opinion has pointed out and reprobated the overwhelming misogyny of the traditional idea that maligned certain women at critical moments of the past centuries, calling them witches and conspiratorial enemies against the Christian faith through a diabolical pact and fantastic transgressive activities, such as flying night and attendance at covens. In this ideological and social construction, treaties against magic and superstitions collaborated directly. However, there is still a lack of analysis and discussion regarding the way in which demonological treaties linked women to magical practices and how that opinion was reproduced through different texts dedicated to control, as far as possible, any heterodox tendencie.

KEYWORDS: women, witches, censorship, inquisitors, demonology. 